\title{
Esclerose Sistêmica
}

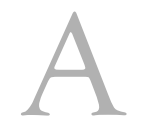

esclerodermia, modernamente chamada de esclerose sistêmica, segue sendo dentre as doenças reumáticas, a mais temível, desde a magistral narração de Carlo Curzio em Napoli (1752). Antes, ela possivelmente havia sido reconhecida pelos sábios da Medicina Helênica, dentre eles, Hipócrates, 460 a.C.

Séculos mais tarde, William Osler (1892) teria dito que a enfermidade tinha um prognóstico sombrio. Tratava-se de moléstia crônica de longa duração, de meses (lê-se aqui, aqueles com morte precoce) a muitos anos. Os doentes sucumbem de complicações pulmonares ou renais. Distúrbios reumáticos têm sido referidos em algumas ocasiões; em outras, os cardiovasculares.

Estudioso da esclerodermia, Osler considerou-a como a mais temível de todas as doenças do homem por sua complexidade clínica tão grande, e não poupando sequer um único sistema ou órgão.

É notável ver o número sufocante de ilustres personalidades médicas do século XVIII e XIX que contribuíram com a sua nosologia, dentre eles Villan, Alibert, Kaposi, Opie, Hutchinson, Raynaud, Addison, Murphy, Forestier e tantos outros, cada qual, por seu notório saber nas áreas internas correspondentes.

A doença não é tão freqüente, porém, nem tão rara assim. A incidência nos Estados Unidos gira em torno de 19 casos por um milhão por ano e sua prevalência é extremamente variável entre 19 e 75 casos/ano por 100.000 habitantes. Estima-se lá, a existência entre 40.000 e 165.000 casos da doença. Tal variação reside no fato de incluir, ou não, pacientes com casos moderados da enfermidade que não preenchem os critérios diagnósticos do Colégio Americano de Reumatologia (ACR).

Extremamente incapacitante, a esclerose sistêmica exige mesmo que dela se ocupem um grupo de médicos nas diversas áreas da medicina interna, porquanto atingindo indistintamente a todos os sistemas, é justo imaginar a complexidade do seu acompanhamento clínico, por um só especialista. Basicamente, é o reumatologista que tem esta abrangência clínica, por tratarse de uma desordem do tecido conjuntivo. Há momentos, porém, que é inquestionável a colaboração da pneumologia, nefrologia, vascular, dermatologia etc.

A Revista Brasileira da Reumatologia houve por bem fazer um número especial sobre esta enfermidade, organizado por Percival D. Sampaio-Barros, que na UNICAMP incumbiu-se desta matéria, juntamente com João Francisco Marques Neto, outrora nos anos setenta, pioneiro no estudo desta enfermidade neste país.

Os trabalhos, na sua quase totalidade, são de natureza clínica, dentre eles um estudo sobre o escore cutâneo no estadiamento da enfermidade, que permite identificar distintos padrões da esclerose sistêmica, principalmente com respeito a forma limitada e difusa.

Outros são de natureza cardiovascular, principalmente o da prevalência da hipertensão pulmonar de prognóstico menos favorável. Contribuição importante é também o estudo sobre a pressão venosa periférica, que guarda uma certa relação com o aparecimento de úlceras isquêmicas nas extremidades.

A capilaroscopia, que data de longos anos, primeiramente no lúpus eritematoso sistêmico, tem sido resgatada nestas três últimas décadas por Luis Eduardo Andrade, como excelente recurso propedêutico nas enfermidades difusas do tecido conjuntivo, com padrões mais ou menos distintos. Estes postulados foram eficazmente bem demonstrados por João Carlos Tavares Brenol e seu grupo, com uma clara e até inequívoca relação entre capilaroscopia e o grau de comprometimento de órgãos alvos na esclerose sistêmica. Neles a doença pulmonar ativa pode ser detectada precocemente, com chances, portanto, de um tratamento mais precoce, sobretudo em nossos dias, e de melhor prognóstico.

Este número especial contém ainda apresentações em forma de resumos e relatos de casos sumamente interessantes para acumular maior experiência clínica, incluindo a crise renal como manifestação inicial da enfermidade, o uso de clodronato, que revelou-se eficaz na mobilização da calcinose intersticial com resolução cicatricial de algumas úlceras das extremidades, o tratamento cirúrgico da doença de refluxo na esclerose sistêmica etc. Um estímulo à leitura, são também os poucos resumos e poucos trabalhos sobre as alterações de auto-imunidade encontradas nesta enfermidade. Ela é, todos sabemos, juntamente com a dermatomiosite, sensivelmente mais pobre em relação às demais enfermidades do tecido conjuntivo com respeito aos achados sorológicos.

Estas duas enfermidades, sem exagero, permanecem ainda dentro daquele conceito unitário dos anos trinta, sob um único denominador comum intitulado fibrinóide, proposto por Klemperer e seus colaboradores em Das Colagenosis. 
Escusado é dizer que este conceito meramente histomorfologócico não atendia às expressões clínicas de diferentes enfermidades de uma mesma alteração anatômica, ou seja, o fibrinóide. Ela cedeu lugar, portanto, àquelas alterações sorológicas dos anos quarenta, conferindo maior identidade a cada uma das doenças difusas do tecido conjuntivo e que duram até os nossos dias.

O que se percebe dos artigos, resumos e relatos de casos é o desejo inflexível daqueles que se dedicam a esta enfermidade, de se unirem em torno deste tema. Nota-se, por exemplo, em alguns relatos, que eles já trabalham de forma colaborativa em estudos multicêntricos, trocando informações entre as diversas unidades universitárias ou não deste país. O GEPRO
(Grupo de Esclerose Sistêmica do Projeto Pronuclear), coordenado por Percival D. Sampaio-Barros, é um dos braços do Projeto Pronuclear que, sob a direção de Luis Eduardo Andrade, já está institucionalizado pela Sociedade Brasileira de Reumatologia, representando justamente o começo, o vértice desta imensa e enigmática pirâmide nosológica, a esclerose sistêmica, onde muito ainda existe por se descobrir.

ADIL MUHIB SAMARA

Professor Titular Disciplina de Reumatologia Departamento de Clínica Médica Faculdade de Ciências Médicas Universidade Estadual de Campinas 